\title{
Author Correction: Mitochondrial proteins: from biogenesis to functional networks
}

\section{Nikolaus Pfanner (iD, Bettina Warscheid and Nils Wiedemann}

Correction to: Nature Reviews Molecular Cell Biology (2019) https://doi.org/10.1038/10.1038/s41580-018-0092-0, published online 09 January 2019.

In the original versions of figures 1 and 4, the respiratory complexes were shown in the wrong orientation. These errors have now been corrected in the HTML and PDF versions of the article.

https://doi.org/10.1038/s41580-021-00361-x I Published online 23 March 2021

(c) Springer Nature Limited 2021 